\title{
ALTERNATIVAS DEL PODER POLÍTICO EN LOS MOVIMIENTOS SOCIALES-RURALES DE COLOMBIA: CASO ORGANIZACIÓN INDÍGENA DEL NORTE DEL CAUCA*
}

ALTERNATIVES OF POLÍTICAL POWER IN THE SOCIAL-RURAL MOVEMENTS OF COLOMBIA: CASE OF THE INDIGENOUS ORGANIZATION FROM NORTH OF CAUCA

\section{NERY BECA MASAGUALLI* ÓSCAR DAVID LAGARES BOLAÑO***}

\section{R E S U M E N}

La autonomía indígena ha jugado un rol fundamental en la pervivencia de la cultura tradicional y en la adquisición de bienes simbólicos. La aplicabilidad de dicha categoría ha llevado al pueblo Nasa a generar espacios de participación social propios de dicha comunidad, cuya finalidad ha estado enfocada en atacar la presencia cultural de la occidentalización. La investigación tuvo como referente metodológico el estudio de caso; la recolección de datos por medio de la asistencia a las asambleas comunitarias y en la participación de los ejercicios de recuperación de tierras en el caso del Resguardo indígena Nasa de Corinto. La aplicabilidad del método científico dio como resultado el análisis del concepto de autonomía y su forma de ejercer control social en los territorios ancestrales, ejemplo de la ejecución de alternativas de poder socio-político.

PALABRAS CLAVE: identidad, representaciones sociales, resistencia social, autonomía indígena, territorio.

\section{A B S T R A C T}

Indigenous autonomy has played a fundamental role in the survival of traditional culture and in the acquisition of symbolic goods. The applicability of this category has led the Nasa people to generate spaces for social participation that belong to that community whose purpose has been focused on attacking the cultural presence of Westernization. The research had as a methodological reference the participant observation, the data collection by means of the assistance to the community assemblies and in the participation of the land recovery exercises. The applicability of the scientific method resulted in the analysis of the concept of autonomy and its way of exercising social control in the ancestral territories, an example of the execution of socio-political power alternatives.

KEYWORDS: identity, social representations, social resistance, indigenous autonomy, territory.

\footnotetext{
*El presente artículo científico es el resultado de investigación del proyecto titulado "alternativas de poder político en las organizaciones indígenas de Colombia, propuestas colectivas para la aplicación de la autonomía indígena". Trabajo de investigación Financiado por la Fundación para el buen vivir y la protección de la vida "Nasa pal"; Fundación Nasa pal.

* Magíster en Ética y filosofía política de la Universidad del Cauca (Popayán, Colombia). Docente investigadora de la Institución Educativa Natalá (Colombia). Vereda Natalá Resguardo San Francisco Toribío, Cauca. Código Postal: 192001, Toribio, Colombia. Correo electrónico: nerytech@hotmail.com

** Sociólogo de la Universidad del Atlántico. Docente investigador de la Institución educativa Natalá (Colombia). Vereda Natalá Resguardo San Francisco, Toribío, Cauca. Código Postal: 192001, Toribio, Colombia. Correo electrónico: oscarlagares@gmail.com
} 


\section{INTRODUCCIÓN}

Toribío, según el Plan de Desarrollo 2015 - 2019 (2015), tiene una extensión de 49.504 hectáreas y una población estimada en 28.561 habitantes, en la cual el 97\% de ellos son indígenas; está situado en las estribaciones de la cordillera Central, al nororiente del Departamento del Cauca. "Hacen parte del municipio el corregimiento de La Despensa (Río Negro) y las inspecciones de policía de El Tablazo, La Cruz, López, Natalá, San Francisco, Santo Domingo y Tacueyó" (Alcaldía de Toribío, 2015, p. 31), ver mapa 1. Sin embargo, son sus tres resguardos Nasa (Toribio, Tacueyó y San Francisco), los que integran la estructura

\footnotetext{
' Los pueblos indígenas desde hace muchas décadas, trabajan bajo proyectos comunitarios para su sostenimiento, progreso económico y vigencia de costumbres propias. En los territorios se les conoce a dichos trabajos de convivencia como planes de vida. Estos proyectos están reconocidos legalmente por las organizaciones gubernamentales locales, regionales y nacionales. El término empezó a ser usado hacia 1970 en cabeza de Álvaro Ulcué Chocué (asesinado en 1984); quien, siendo indígena Nasa del norte del Cauca, estudió teología hasta ser cura párroco franciscano. Álvaro Ulcué fue líder comunitario y fomentó la resistencia cultural indígena. Su idea de proyecto o plan de vida para nativos incluía temáticas indígenas y no indígenas que pudieran adherirse en conjunto a cualquier gobierno de turno, favoreciendo el saber milenario. Ver: Cátedra Nasa, UNESCO, 2002, p. 34.
}

indígena llamada Plan de Vida Proyecto $\mathrm{Nasa}^{1}$, cada cual con su propio cabildo ${ }^{2}$.

Figura 1. Ubicación geográfica del municipio

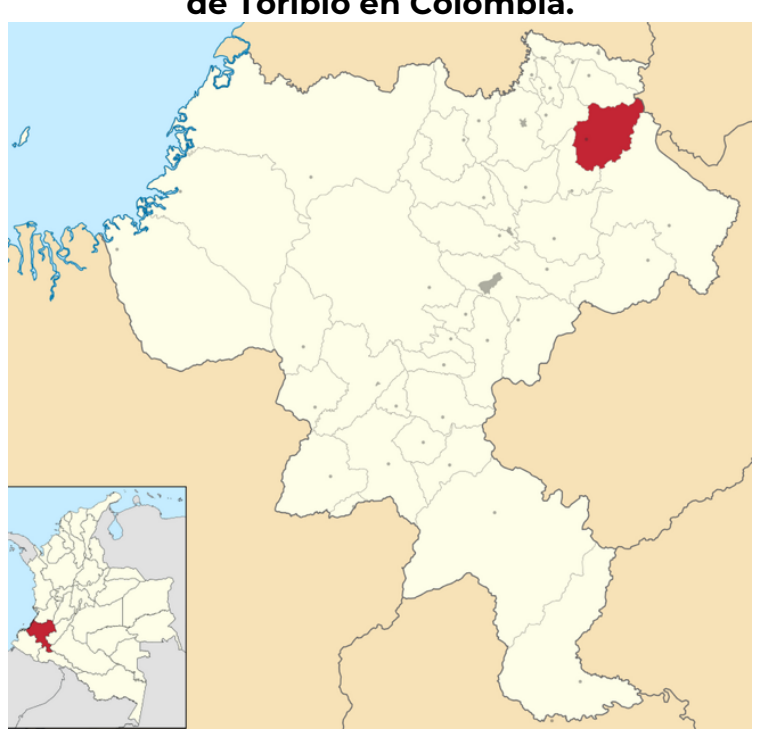

Fuente: https://es.wikipedia.org

El territorio es montañoso, lo cual permite comprender que es un corredor geoestratégico, pues une los departamentos del Cauca, Valle, Huila y Tolima, atrayendo intereses del narco- 
tráfico y los grupos armados, de hecho, Archila y González (citado por Beca, Maya y Opocue, 2017) consideran que:

El pueblo Nasa es uno de los grupos poblacionales que más ha sufrido la guerra: En términos de acciones violentas contra los indígenas colombianos: entre 1974 y 2004 ella fue objetivo de 2414 acciones represivas, entre ellas 1259 detenciones arbitrarias, 565 asesinatos políticos, 109 amenazas y 43 desapariciones forzadas. (p. 53)

Respecto a su diversidad climática, esta produce gran variedad de productos agropecuarios, como hortalizas, tubérculos, frutas, aves y peces, empero, es más conocido a nivel nacional por sus cultivos de uso ilícito (Marihuana y Coca) que a su vez fue asociado al conflicto armado entre las FARC-EP y el Estado colombiano.

El tema de los cultivos de uso ilícito es un asunto permanente en la agenda de las organizaciones indígenas, pues "influyen en el cambio de patrones culturales y las dinámicas sociales de los jóvenes" (Beca et al., 2017, p. 54); ya que, "con su presencia ponen en riesgo la identidad Nasa e interfieren en los procesos que construyen plan de vida para la comunidad" (ob., cit, p. 54).
Pese a ello, la intimidación y la persecución, no limitan la organización indígena, sino que, por el contrario, éstos sujetos colectivos Nasa, cuentan con diferentes instancias de resistencia social; una de las más reiteradas son los Mandatos que surgen de las Asambleas Comunitarias, pues allí se establecen normas de pervivencia y desarrollo autónomo blindando su autodeterminación indígena por fuera del conflicto armado.

Por lo tanto, analizar los modos de resistencia que presenta la comunidad indígena Nasa ante las adversidades del conflicto armado, hace que los mecanismos de sobrevivencia se sobrevaluen entorno a la manera en cómo se percibe la dinámica social. En este sentido, el estudio de caso, tal cual como lo caracteriza Peña Collazos (2009), que:

Analiza fenómenos complejos en el tiempo, con escenarios sociales que cambian constantemente, con dinámicas de interacción de difícil interpretación. (...) El Estudio de Caso permite estudiar los eventos, acciones, relaciones y comportamientos de las redes sociales en sus escenarios propios. Además, por ser un fenómeno holístico, requiere la provisión de varias fuentes de infor- 
mación que permitan cubrir todos los frentes para una mayor comprensión de la realidad (p. 188).

Igualmente, el análisis de las prácticas de resistencias de este grupo étnico se muestra como una herramienta muy importante en ciertas situaciones, debido a que los distintos actos característicos del entorno social se interiorizan como punto de partida para el entendimiento de la economía ilegal. En esta medida, la identidad, la autonomía $^{3}$ y la cultura en defensa del territorio 4 , como madre, se quedan ahogados en ese espacio. Las posturas indígenas en defensa del territorio, los derechos ancestrales y las ideas para una vida más digna con reciprocidad hacia la madre tierra, se entrelazan y exponen a la luz del milenio la importancia social, política y cultural de los significados de territorio, prácticas espaciales, pero quizá la estrategia no es la más pertinente, puesto que no se trata de imponer la concepción de tierra, territorio y territorialidad, sino avanzar hacia la concientización; pues para la

\footnotetext{
${ }_{3}^{3}$ Para la Defensoría del Pueblo "la autonomía es entendido como la facultad de los grupos étnicos de diseñar su proyecto integral de vida, en el que deciden su destino, considerando su pasado cultural y su realidad actual para prever un futuro sostenible de conformidad con sus usos y costumbres. También, se considera como la facultad que tienen de organizar y dirigir su vida interna de acuerdo con sus propios valores, instituciones y mecanismos dentro del marco del Estado del cual forman parte". Defensoría del Pueblo (Febrero, 2014). Derecho a la autonomía
}

enseñanza del cura católico Nasa, Álvaro Ulcué Chocué, "era urgente organizar la gente, capacitarla, formar maestros indígenas que enseñaran en su propia lengua, tomar conciencia sobre la territorialidad y sobre la cultura" (Instituto para Misiones la Consolata (IMC), 2011, p. 143).

En Colombia, las acciones sociales del movimiento indígena reflejan alternativas de poder político, pues a partir de las diversas luchas han venido ganando espacios de confrontación, soberanía popular y mejor aún de autonomía. Para ello, ha sido necesaria la construcción de espacios comunitarios de pensamiento y acción a través del tiempo, por ejemplo, desde los Nasa, mantener la idea propia de desarrollo desde la identidad, se ha logrado en gran parte, al accionar comunitario constante, tocando esferas locales, regionales o nacionales; algunas veces mediante la movilización, otras veces, haciendo uso de leyes propias o del Estado, todo ello porque su identidad, respecto a la noción de tierra, si-

de los grupos étnicos, (pp 1-5). Recuperado de http://www.defensoria.gov.co/public/pdf/04/boletin2etnicos.pdf

${ }^{4}$ Las acciones culturales propias de la comunidad indígena Nasa como la ritualización es un ejemplo claro del uso espiritual para proteger la ancestralidad. Para este caso, la cultura del ritual se pone en práctica para dar cabida a la defensa de los territorios indígenas ocupados por los grandes terratenientes. 
gue siendo de arraigo mítico milenario, aunque las culturas no son estáticas, sino que se transforman debido a múltiples factores a través del tiempo/ espacio; y así lo evidencia el pueblo Nasa, el cual no es ajeno al multiculturalismo, la modernidad y la globalización actual:

La tierra no es solo un espacio que les da de comer. Para los indígenas la tierra tiene un sentido espiritual. A los Nasa, por ejemplo, les entierran el ombligo en una tulpa para que estén amarrados al territorio. Yo he escuchado expresiones entre los Nasa que dicen que por un pedazo de tierra se hacen matar, porque para ellos es como la madre que les da el alimento, pero también es el sitio en donde ellos pueden conectarse con otras cosas. Además, dicen que la tierra no es de ellos, sino que es un préstamo de sus hijos, por eso deben cuidarla y mantenerla sana 5 .
Sin embargo, investigaciones como las de Macos Yule y Carmen Vitonás ${ }^{6}$, permiten recoger las nociones Nasa de tierra, territorio y territorialidad como un principio fundamental de vida y permanencia Nasa.

Por lo anteriormente mencionado, esta investigación expone dos hechos, que si bien no son nuevos, en las últimas décadas se ha presentado de manera reiterativa en el Norte del Cauca ${ }^{7}$ : uno, es la llamada recuperación de tierras en Corinto y el segundo es la aplicación de la justicia indígena propia en Toribío ante los actores armados, pues en ambos casos se hace uso de las normas constitucionales colombianas vigentes y las leyes internacionales, además de las milenarias indígenas Nasa, pero que desde el Estado colombiano poco se hace para hacerlas valer. Estos dos espacios como acciones innegables de la autonomía indígena, conllevan a la práctica del buen vivir (wët wët fxi'zenxi) $^{8}$ que tan negado parece a la población indígena Nasa.

\footnotetext{
${ }^{5}$ Entrevista realizada al cronista José Navia, publicado por la organización Hacemos Memoria en octubre de 2017 bajo el título "La tierra es como la madre: Pueblo Nasa" redactada por Esteban Tavera. Más acerca de la entrevista en http://hacemosmemoria.org/2017/10/18/la-tierra-es-como-la-madre-pueblo-nasa/

${ }^{6}$ La investigación acá citada de Marcos Yule Yatacué y Carmen Vitonás se debe al texto Pees Kupx Fxi'zenxi "la metamorfosis de la vida". "Pensar, mirar y vivir desde el corazón de la tierra", Nasa üsa's txi'pnxi "cosmovisión Nasa". Publicado por Proyecto Nasa en el 2012.

7 Se conoce como "Norte del Cauca" a una subregión del departamento del Cauca que
}

queda en el extremo norte de este y límita con el sur del departamento del Valle del Cauca. Hacen parte los siguientes municipios: Caloto, Toribío, Jambaló, Caldono, Santander de Quilichao, Suarez, Guachené, Corinto, Miranda y Buenos Aires.

${ }^{8}$ Acosta (2010) considera que el buen vivir (que hace parte de la cosmovisión indígena Nasa) es una categoría en permanente construcción y reproducción. No está inmersa en la idea de desarrollo occidental, pues "los bienes materiales no son los únicos determinantes. Hay otros valores en juego: el conocimiento, el reconocimiento social y cultural, códigos de conductas 
Teniendo en cuenta la experiencia expuesta con anterioridad, se destaca la movilización social, la cual, "se produce a partir de incentivos que surgen de los cambios coyunturales que a veces se presentan en el contexto, especialmente en el entorno político, e inducen a que la gente participe poniendo en juego sus intereses" (Hernández Lara, 2003, p. 111). Dicha movilización social recae bajo la idea de que "los actos de resistencia pueden ser pues analizados como acciones colectivas" (Op., cit, p. 111).

Se espera que en el transcurso del texto se logre poner en conocimiento, cómo el concepto de autonomía indígena Nasa, se manifiesta en las acciones antes mencionadas y expresan el camino de resistencia social y su idea de "buen vivir", puede trastocar los sentires nacionales para un cambio menos violento y más unido a la idea de diálogo y acción de resistencia civil.

\section{TIERRA, TERRITORIALI- DAD Y AUTONOMÍA}

La tierra es la madre, la hermana y ha dejado innumerables espacios que le oxigenan, debido a ello, la comunidad Nasa no se siente dueña de la tierra,

éticas e incluso espirituales en la relación con la sociedad y la Naturaleza, los valores humanos, la visión de futuro, entre otros" Para mayor profundización consultar el texto "El buen vivir en el camino del post-desarrollo. Una lectura desde la Constitución de Montecristi". Recuperado en: sino al contrario, le expresa agradecimiento por su compañía, frutos, amor, educación y riqueza cultural. El Nasa constantemente mediante una serie de ritualidades individuales y/o colectivas, se comunica con ella, la madre. Busca mantener una relación armónica con el espacio físico y espiritual que es ella quien, de una manera amable, le permite habitar. Así lo hace notar Hernandez Lara (2003):

La vida es concebida entre los indígenas como algo que habita en los seres humanos, pero también en los animales, los vegetales, los minerales y, por extensión, en toda la naturaleza. La defensa de la vida, por lo tanto, es la defensa de la naturaleza toda y dentro de ella especialmente la protección de la madre tierra. No es sólo el derecho a la vida de las personas, constitucionalmente establecido como un derecho primordial en Colombia, sino que es más que eso lo que este movimiento defiende cuando se refiere a la vida (p. 121).

https://www.fuhem.es/media/cdv/file/biblioteca/Analisis/Buen_vivir/Buen_vivir_posdesarrollo_A._Acosta.pdf 
Así pues, el territorio es el espacio que comparten todos los Nas nas (animales, plantas, personas e incluso seres que otras culturas consideran inertes como las piedras), con los espíritus de la naturaleza: el de la tierra, el agua, el viento, el trueno o espíritus protectores como el duende. El territorio es poseedor de vida propia y se reconfigura la comunicación espiritual también, gracias a los the' walas (Chamanes de este pueblo). Aunque hay Nasas en distintas zonas geográficas: Cauca, Huila, Valle del Cauca y Putumayo especialmente, la idea de territorio es una sola: es donde se comparte y se recrea la identidad, el idioma y las costumbres de ser recíprocos con la tierra, con la naturaleza puesto que permiten recrear y forjar su permanencia como pueblo.

Otra situación interesante en su estrategia de autonomía colectiva ${ }^{9}$, ha sido que el movimiento indígena como organización social busca constantemente que las relaciones sociales no

\footnotetext{
${ }^{9}$ El concepto Nasa de autonomía está basado en la normatividad constitucional del Estado colombiano: bajo los artículos 12, 13, 20, 29 y 30 (que se ratifica en el derecho internacional de los pueblos indígenas señalado en el convenio 169 de la OIT de 1989 en su artículo 13), la ley 21 de 1991, el auto 004 de 2009 y el decreto de ley 1953 de 2014. Donde "la Corte Constitucional definió este derecho como el poder de elegir su propio destino, optar por una determinada forma de vida, organización económica, utilización del espacio y los recursos naturales de la mejor manera que convenga a sus particulares y variados intereses" (citado por Sánchez, Pardo, Flores y Ferreira, 2001, p. 143). Por su parte, la autonomía colectiva se identifica a partir de las acciones que genera la comunidad con base en los dere-
}

sean centradas exclusivamente en los problemas indígenas, sino, que se enfoquen en puntos de trabajos que llamen a la pluralidad, tal y como también lo hacen los movimientos feministas que expresados por Chantal (1999), plantea que el antiesencialismo es la vía de democracia radical que contrapone al pensamiento conservador, contribuyendo así a que exista una real "articulación de distintas luchas ligadas a diferentes formas de opresión" (p. 108).

El pueblo indígena Nasa, por ejemplo, según Rueda Ortiz, Fonseca Díaz y Ramírez Sierra (2013), ha sido el que presenta mayor influencia con respecto a la recuperación de la tierra, propuesta de lucha que durante muchos años lideran de manera organizada y consecuente. Así que no desaprovechan espacios sociales, políticos electorales, culturales y de movimiento social para aunar sus reivindi-

chos Internacionales y nacionales mencionados, y también desde su cosmovisión Nasa: Ley de Origen y Derecho Mayor. La autonomía colectiva Nasa se ve reflejada en las prácticas sociales que tiene la comunidad para ejercer sus propias leyes y normas, por ejemplo, el accionar colectivo que estos realizaron en Julio de 2012 cuando la organización indígena de Toribío convocó, en su aplicar de la autonomía, a toda la población a realizar un ejercicio de control territorial en el que se obtuvo como resultado la expulsión de militares activos asentados en un sitio considerado sagrado. Para profundizar dicho evento consultar: https://www.elespectador.com/noticias/judicial/indigenas-expulsan100-soldados-de-base-militar-del-cau-articulo360673 
caciones que no desean ser exclusivistas, sino por el contrario, más incluyentes en medio de la diferencia.

Quizá si hay algo de lo que parte el pensamiento indígena en su reivindicación más importante y es lo que lo hace a unirse a otros grupos, identidades y luchas es precisamente los conceptos de territorialidad y tierra. Es decir, la comunidad Nasa no se siente dueña de la tierra, sino al contrario, le expresa agradecimiento por su compañía, frutos, amor, educación y riqueza cultural; hay una comunión desde el ser indígena que lo une a todos los grupos sean afrodescendientes, feministas, homosexuales o de cualquier orientación y es su relación identitaria con respecto a la relación individuo-naturaleza, ya que son miles las personas que creen que el telos de la humanidad ha de ser el convivir en armonía con la naturaleza a la que también consideran madre, igual que los Nasa y muchas poblaciones originarias y esa forma de sentir la vida y la naturaleza, gracias a la Internet y a la realización de videos con mano de obra indígena, ahora es más conocida que en décadas anteriores.

\footnotetext{
10 Durante las asambleas comunitarias muchos indígenas Nasa han considerado al ejercicio de cultivar marihuana fundamental para la economía familiar. Las actas analizadas de las asambleas veredales, organizadas por el Cabildo Indígena de San Francisco y Tacueyó, el cual se tuvo acceso, hacen notar que muchas familias viven de la marihuana. Su forma de ingreso familiar es cultivar la hoja de coca (para el procesamiento
}

Es pues que las acciones de resistencia social dadas en el movimiento indígena del Cauca se solidifican hacia una propuesta alternativa con respecto a la construcción de soberanía entre todos y todas, quienes sientan que no se les incluye en el sistema de representaciones políticas y ven diezmadas sus posibilidades de acenso social.

\section{1. El territorio y su tenencia agrí- cola}

El municipio de Toribío en su mayoría es indígena y sus tierras son aptas para sembrar cultivos importantes como el café con 2.117 hectáreas y el maíz con 320 hectáreas sembradas (Alcaldía de Toribío, 2015). A pesar de ello, la siembra de cultivos de marihuana, en una región afectada por la guerra, ha sido de una utilidad preponderante para un sector de la comunidad indígena Nasa ${ }^{10}$. Fomentar una economía ilegal, pero eficaz, ha sido una manera de sobrellevar una vida social en el territorio, esto debido a las acciones colectivas de los cultivadores de coca y marihuana asociados en la cooperativa CAUCANNABIS ${ }^{11}$.

en laboratorios artesanales y de ahí adquirir la pasta de coca o base de coca) y la marihuana.

"Esta cooperativa consiste en transformar los cultivos de marihuana y coca en productos medicinales, su función es extraer la materia prima de la hoja de coca y la marihuana para crear productos como las pomadas para los dolores mus- 
Las ganancias económicas que deja la marihuana son de gran utilidad, pues el valor de esta oscila entre los \$ 60.000 (USD) a más de \$1’o0o.00o (USD) por kilogramo (Oficina de las Naciones Unidas contra la Droga y el Delito [UNODC], 2016). El valor comercial de la marihuana varía según su contenido de THC (tetrahidrocanabinol, ingrediente activo de la marihuana); el dinero es repartido entre los cultivadores dueños de la tierra y se paga a los indígenas que trabajan en el proceso de corte y clasificación de la marihuana. Los comuneros encargados de "limpiar" la flor de marihuana se les conoce como peluqueadores o peluqueros, debido a que se dedican a "peluquear" los racimos de marihuana para su distribución; el pago de estos comuneros "peluqueadores" es de \$20.00o por kilogramo de marihuana "limpiado".

Según los documentos analizados, en la cooperativa CAUCANNABIS existen entre 200 y 300 familias adscritas en el municipio de Toribío solamente, es decir, que cultivar marihuana representa para la comunidad toribiana un acomodamiento presupuestal muy

culares, por ejemplo. Debido a frecuentes discusiones internas entre comuneros defensores de la organización indígena y detractores de esta frente al tema de los cultivos de uso ilícito, estos detractores pusieron en función la creación de dicha cooperativa. Para mayor información consultar: http://www.caucannabis.com

12 Para la Federación Nacional de Cafeteros, FNC, el precio interno de referencia del café colombiano para la bolsa de Nueva York es de importante, ya que si se compara el valor de la marihuana con el del café (cuyo valor monetario es de $\$ 4,100$ el $\mathrm{kg}$ en el mercado internacional ${ }^{12}$ ), se es muy rentable cultivar la marihuana, debido a ello, la siembra de esta ha terminado por reemplazar el cultivo de café.

El ejercicio de cultivar la planta es exigente pues debe cumplir con los estándares de calidad del producto para el consumo masivo. Las familias cultivadoras indicaron que su mayor dificultad, con respecto a su cuidado, deviene cuando se presentan muchas lluvias pues se generan hongos en las flores. Así lo hace saber la comunera Nasa, Doña Flora ${ }^{13}$ :

Siempre nosotros tenemos que tener mucho cuidado con las plantas, ellas son muy delicadas y costosas, tenemos que ver que la tierra maneje su temperatura para que la mata de sus flores en no más de tres meses. Es muy difícil porque esta es una zona de constantes lluvias y menos mal que tenemos esos bombillitos para que se mantenga en calor.

4,100 COP y su precio externo es de 123.10 a 127.95 USCent/lb. Estos datos oficiales identifican el valor que presenta el café para el mercado global. Consultar: https://www.federaciondecafeteros.org/static/files/precio_cafe.pdf

13 Datos propios de la investigación, nombre cambiado a petición de la entrevistada. 12 de abril de 2017, vereda "La Despensa", zona rural de Toribío, Cauca (Resguardo de San Francisco). 
Por otro lado, para acelerar el proceso, se construyen invernaderos, es decir, que por cada familia cultivadora de marihuana existe uno o más invernaderos, lo cual se infiere (basado en los análisis de datos de Caucannabis) que en Toribío existen más de 500, ya que en los datos registrado hubo un promedio de dos invernaderos por familia registrada en la cooperativa. Dichos invernaderos (ver figura 2), al utilizar energía eléctrica constantemente, generan en ocasiones cortes de energía eléctrica debido a la sobre carga, pues el consumo promedio de la zona, se compara con el de una ciudad mediana, es decir, que el municipio de Toribío (cuya población equivale a más de 25.00o habitantes) está consumiendo los mismos watios de energía de una ciudad de 100.000 habitantes.

Figura 2. Invernaderos de marihuana, mirada nocturna de las montañas de Toribío

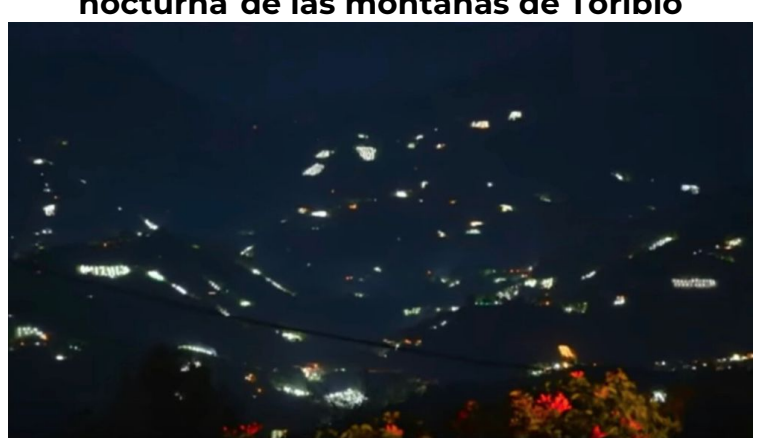

Fuente: La Mota, Blog. (2015). El interminable ocaso de la ciudad perdida de la marihuana. [Entrada de Blog]. Recuperado de https://www.lamota.org/es/blog/ocaso-ciudadperdida-marihuana/

A pesar de ello, las familias cultivadoras consideran de gran ayuda económica la siembra y venta de marihuana con fines recreativos a personas provenientes de las ciudades cercanas al territorio como Santander de Quilichao y Cali, por ejemplo (Ver figura 3).

\section{Figura 3. Ruta de la marihuana en el Norte del Cauca.}

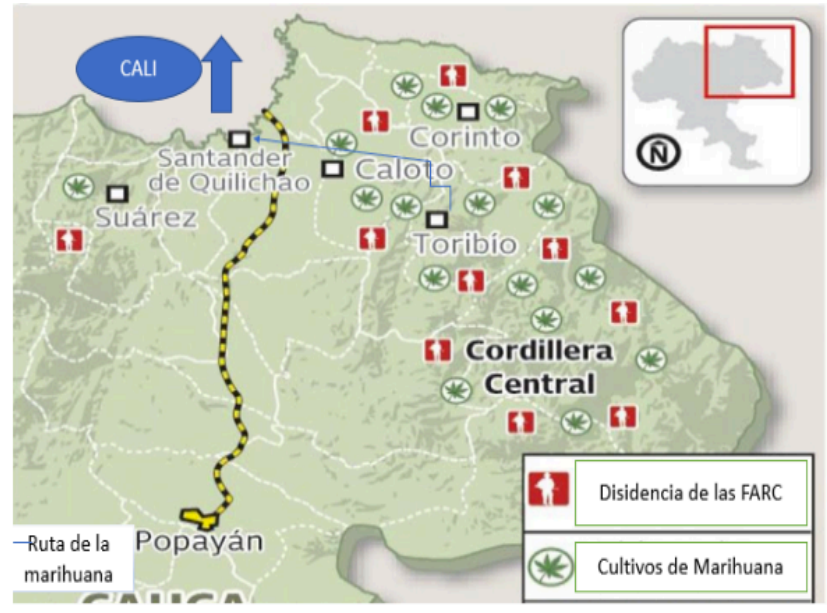

Fuente: El país (2017). Por los cañaduzales del Valle sacan droga para Chile y el Caribe, (Diario el País, 1 de marzo de 2017). Recuperado de: http://www.elpais.com.co/judicial/por-los-canaduzales-del-valle-sacan-droga-para-chile-y-elcaribe.html

\section{2 Autonomía indígena y legisla- ción occidental}

Hacia los años ochenta, las luchas indígenas que enaltecen las nociones de dignidad y derechos sobre la tierra y sobre sí mismos (nociones muy propias de un momento histórico), hicieron que sugieran nuevos significados a espacios político-culturales que escapan a los sentires eurocentristas: el sujeto colectivo tuvo mayor primacía sobre el individual (pero con matices distintas a las teorizadas desde lo liberal) pues la comunidad asume términos foráneos y los apropia hacia sus 
necesidades, para reclamar ante el Estado la real ejecución de leyes y normas vigentes. Archila y González (2010), frente a este punto consideran que:

Las organizaciones indígenas son conscientes de la construcción instrumental que hacen de sus identidades y adoptan en la práctica un punto de vista pragmático, especialmente para su acción gremial y política. Como se puede ver, son estrategias políticas del movimiento indígena para relacionarse con los otros externos: a veces desde su particularidad y a veces desde lo común con otros sectores sociales subalternos (p. 17).

Es así que el Congreso Regional indígena del Cauca como movimiento indígena, organizó su Plataforma de Lucha desde 1971 nutriéndose de los conceptos que le plantee la actualidad política, las teorías del momento. Tal y como lo menciona Zibechi (2008), son esas nuevas formas del movimiento social o sociedades en movimiento, ejerciendo que se aprecie al sujeto social de manera distinta a la que venía ocurriendo en los años 70.
Ya en 1991, la Constitución Política de Colombia, reconoce la diversidad cultural del espacio geográfico - social naciona ${ }^{14}$ lo cual, respecto al tema de reivindicación y uso de los derechos ganados, genera serios tropiezos pues las imposiciones occidentales, como únicas formas de vida conocidas, empiezan a perder terreno, pero no solo como emancipación ilógica, sino como Derecho válido en todos los espacios sociales, políticos, educativos y culturales.

$\mathrm{El}$ auge de la sociedad discriminadora, represora, de pensamiento euro-centrado que aún existe, pone las razones y filosofías indígenas, muy por debajo de las esferas culturales occidentales donde el principio son los griegos y luego se pasa por teóricos franceses, ingleses, alemanes o rusos y su idea del "deber ser". Dussel (2000) resume lo anterior de la siguiente manera:

En el renacimiento italiano (especialmente después de la caída de Constantinopla en 1453), comienza una fusión novedosa: lo Occidental latino (secuencia c del esquema), se une con lo griego Oriental (flecha d), y enfrenta el mundo turco, el que, olvidando el origen helenístico-bizantino del
14 Convención 169 de 1989 la OIT en sus artículos 5, 26, 27 y 28, ratificada en la Constitución Política de Colombia: Ley 21 de 1991 y artículo 7" el
Estado reconoce y protege la diversidad étnica y cultural de la nación colombiana". 
mundo musulmán, permite la siguiente ecuación falsa: Occidental $=$ Helenístico + Romano + Cristiano. Nace así la "ideología" eurocéntrica del romanticismo alemán (p. 26).

Por lo tanto, el devenir indígena queda relegado a simples mitos en sentido fantástico/ maravilloso y no son tomados como saberes, culturas, formas de vida filosóficas. Es decir, que la calificación de sujetos ininteligentes que se dio a la población indígena o afro, en la Colonia sigue presente hoy en día, logrando que sus cientificidades sociales, sus angustias políticas, éticas, sus aportes a la conservación de las especies y la idea de tierra como madre, sea, todo ello en conjunto, comprendido como atraso. El sentido de autonomía política y lucha por la tierra son vistos entonces, como una excusa para hacerse notar por nada.

Según Quijano (2000), luego de las imposiciones ideológicas llegadas con la conquista y afianzadas en la colonialidad, dan a las comunidades originarias una:

...Reubicación en el nuevo tiempo histórico constituido con América primero y con Europa después: en adelante eran el pasado. En otros términos, el patrón de poder fundado en la colonialidad implicaba también un patrón cognitivo, una nueva perspectiva de conocimiento dentro de la cual lo no-europeo era el pasado y de ese modo inferior, siempre primitivo (p. 221)

En ese sentido, la percepción que se tiene sobre la tierra, resulta chocante, inútil y claramente, en contra del desarrollo de un espacio geográfico ya sea una localidad o un departamento.

\section{3. La lucha por la tierra y la au- tonomía actual.}

Las comunidades indígenas, al pasar los año 70 y 80 , solicitando solución a sus problemas de tierra y de segregación, entrados los noventa y ya haciendo uso de normas constitucionales, siguen su legado histórico de ser herederos no solo de unos mitos sino de las acciones que les conllevan a continuar resistiendo al exterminio, la discriminación y la poca atención por parte del Estado, por ello se hace constante alusión a las normas internacionales como la Convención 169 de 1989 la OIT que en sus artículos 5, 26, 27 y 28 , ratificada en la Constitución Política de Colombia: Ley 21 de 1991 y artículo 7: el Estado reconoce y protege la diversidad étnica y cultural de la nación colombiana" señalan que el Estado está obligado a proteger a los grupos indígenas. Conocer de las leyes occidentales, se convierte en la catapulta 
que renueva las reivindicaciones históricas.

En la historia colombiana, por lo menos en la reciente, los indígenas han sido de las pocas comunidades capaces de confrontar, cara a cara, a ambos actores armados y los han expulsado de sus territorios, como expresión de un cansancio social y colectivo y de desconfianza en las instituciones y agencias del Estado. Esto también implica un mensaje claro para los colombianos: los indígenas asumen el control territorial, social y político de sus tierras y desalojan a los actores del conflicto armado. (Uribe y Rámirez, 2014. p. 12)

\section{3. 1. Guardia indígena: protecto- res de la tierra y hacedores de la autonomía}

La guardia indígena presenta un sin número de funciones sociales dentro del territorio, entre ellas se encuentra el desarrollar estrategias para enfrentar de manera no violenta, los choques entre los diferentes grupos armados en el norte del Cauca, ejerciendo una autonomía antes no vista: visitas casa a casa de los comuneros para manifestarse ante la guerra, realizar videos de las asambleas respecto al tema de la guerra, para luego compartir en las instituciones educativas y acompañar a la comunidad cuando ésta toma la decisión de ir hasta los espacios donde se hallan los grupos armados para exigirles que abandonen el territorio.

Es importante decir que desde el movimiento indígena de la Zona Norte del Cauca han tomado conceptos occidentales que una vez apropiados en los territorios ancestrales son pasados por filtros que les hace identificarles cada vez más con lo local, que con lo foráneo; es decir, los conceptos como comunidad, identidad, autonomía, reciprocidad, unidad, entre otros, tienen un gran peso tanto en lo discursivo como en las acciones de la comunidad, de la misma manera, las palabras soberanía, tierra, territorio y territorialidad cobran gran relevancia al momento de reivindicar derechos involucrando a Afros, campesinos y mestizos habitantes de la ruralidad colombiana, como hermanos herederos del sometimiento y la espoliación colona, incluso, luego de la Chiva Bomba de junio del 2012 y el asesinato de dos guardias indígenas en noviembre de 2014, por parte de la guerrilla de las FARC a plena luz del día, la comunidad no cedió terreno respecto a sus demandas, por el contrario, citó a varias asambleas generales donde el Consejo Regional Indígena del Cauca, CRIC, participó como máxima autori- 
dad zonal, y la entidad ONIC (Organización Nacional Indígena de Colombia) en la cual se conglomeran casi todas las organizaciones indígenas del Colombia, hizo lo propio, generando al final, un apoyo a la comunidad, que segura de tenerla razón sobre una vía no violenta, encausa su camino sobre la base mítica indígena.

Las anteriores acciones crean mecanismos de defensa ante las adversidades presentadas para configurar una cultura autónoma y socialmente aceptada, pues para el caso de la lucha por la tierra en el norte del Cauca, la mente colonizada sugiere que ésta es solo para explotación, carece de vida o espiritualidad.

Desde el eurocentrismo ${ }^{15}$, la tierra es una porción geográfica delimitada, es mercancía, lo cual choca con la idea de la vida ancestral y la tradición cultural indígena en general; el video "Somos Alzados en Bastones de Mando" realizado por el Tejido de Comunicaciones para la Verdad y la Vida de la ACIN, en el 2008, expone, cuál es el imaginario colectivo indígena respecto a la tierra y la territorialidad, frente a las políticas extractivistas del capitalismo, aceptadas por los continuos gobiernos:

Las autoridades... dueñas de Colombia, dueñas de nuestras tierras, en el pasado nos quitaron y ahora tenemos que hacer frente para quitárselas a ellos, por estas tierras son nuestras, porque lo merecemos porque son nuestras, nuestros líderes han derramado sangre, nuestros líderes han muerto, pero ahora nosotros tenemos que luchar ${ }^{16}$.

\section{4. La educación: tejido de resis- tencia, autonomía para la reali- zación de los nuevos poderes sociales.}

Construir un sistema de educación propiamente indígena era apostarle al manejo regional de la formación educativa de los estudiantes que hacían parte de las comunidades. Creando de

texto Colonialidad del poder, eurocentrismo y América Latina. En libro: La colonialidad del saber: eurocentrismo y ciencias sociales. Perspectivas Latinoamericanas. Edgardo Lander (comp.) CLACSO, Consejo Latinoamericano de Ciencias Sociales, Buenos Aires, Argentina. Julio de 2000.

${ }^{16}$ Comunero Nasa en miga de resistencia. Minuto 0:10. Consultar el video en: http://www.desorg.org/titols/somos-alzadosen-bastones-de-mando/ 
esta manera programas educativos indígenas ${ }^{17}$, en la cual, dichos programas tomaron como objetivo la evaluación y construcción de modelos de enseñanza e investigación indígena para rescatar lo antes arrebatado en la educación impartida por la Iglesia Católica y el Gobierno Nacional de Colombia. El CRIC (2011) expone que:

La concepción de la educación como un servicio atenta contra el concepto de Educación Propia, y en lugar de facilitar su funcionamiento, se convierte en un obstáculo, por ello debemos desarrollar nuestro sistema desde la concepción de educación como derecho fundamental siguiendo la línea jurídica, filosófica y social de los tratados internacionales y de la Constitución Colombiana. (p. 10).

Así como lo expone el CRIC (2011), la misma comunidad expresaba su descontento:

La educación antes era pésima, los profesores que venían a ense- ñar eran de otra parte y enseñaban lo que les daba la gana, no enseñaban lo que verdaderamente el indígena necesita $\mathrm{y}$ quizá por esa razón, hubo mucho ataque cuando un niño hablaba su propio idioma, decían qué indios pendejos que no hablan bien. (p.11).

De la misma forma en la que Álvaro Ulcué promovió la educación para el pueblo Nasa en Toribío, también la comunidad organizada bajo los mandatos del CRIC tomó la iniciativa de poner en funcionamiento el Sistema Educativo Indígena Propio (SEIP). Los percances identificados con la propuesta de administrar la educación por las mismas comunidades indígenas ha sido el poco avance con lo llamado etnoeducación.

La importancia de administrar los recursos de la Educación para las comunidades indígenas ha llevado a generar una autonomía con respecto a lo que se quiere enseñar y cómo se debería enseñar; así lo hizo valer el cuarto congreso del CRIC en 1981, el cual expone que "la educación es una herra-

\footnotetext{
${ }_{17}$ Desde la creación del CRIC en 1971, los indígenas del Departamento del Cauca han venido apostándole a la autonomía educativa, desarrollando distintos programas de investigación, los cuales han sido: Programa de Educación Bilingüe, PEB; más adelante llamado Programa de Educación Bilingüe Intercultural, PEBI; Programa Educativo Comunitario, PEC; Sistema
}

Educativo Propio, SEP; Sistema Educativo Indígena Propio, SEIP. Para mayor información consultar el texto Organización del Sistema Educativo Indígena Propio del Consejo Regional Indígena del Cauca, CRIC; publicado por el Programa de Educación Bilingüe Intercultural, PEBI-CRIC 
mienta importante para defender y revitalizar nuestra cultura, es necesario replantearla desde los propios intereses y necesidades comunitarias" (CRIC, 2009, p. 22).

La bandera del SEIP es la pedagogía comunitaria, que "propone validar los espacios educativos culturales, desconocidos por la educación oficial y apropiarnos de la Escuela" (CRIC, 2009, p. 29).

Para fortalecer la educación y por ende la cultura Nasa, el padre Álvaro Ulcué "analizó los problemas de la comunidad y quería formar una comunidad nueva con estas características" (IMC, 20011, p. 141).

- Unida

- Organizada

- Educada

- Trabajadora

- Sin vicios

- Consiente

- Crítica y reflexiva

- Autónoma

- Libre

El ideario de sociedad que pensó Álvaro Ulcué era el fin último de su razón existencial; pensar en una sociedad capaz de auto-gobernarse, unida en la visión del ser Nas nasa. Y fue por esa razón que ayudó a consolidar el Cen-

${ }^{18}$ El Proyecto Nasa se creó en el año de 1980 con el propósito de poner en práctica el pensamiento del Padre Álvaro Ulcué. Los programas tro de Educación, Capacitación e Investigación para el Desarrollo Integral de la Comunidad (CECIDIC), así mismo, logró unir políticamente a los tres resguardos que albergan el Municipio de Toribío: Tacueyó, Toribío y San Francisco con el nombre de "Proyecto Nasa" ${ }^{18}$.

De esta manera el discurso de Álvaro Ulcué logró calar en la cotidianidad comunitaria y trascender en acciones colectivas tendientes a fortalecer los lazos educativos comunitarios que hoy en día se mantienen y que si bien partieron del pensamiento teológico occidental contribuyeron en el arraigo cultural, identitario, cosmogónico Nasa y por lo cual hoy en día se ve reflejado en la existencia Nasa, como un ejemplo de ello es el movimiento juvenil Álvaro Ulcué Chocué.

La experiencia comunitaria con respecto a la formación de un proyecto educativo y organizativo según el padre Álvaro se resume cuando él invitaba a reuniones en Toribío "allá tenemos muchas organizaciones y capacitaciones no solamente de religión, sino por la lucha de derechos de la ley Nasa y no solo para rezar, sino reunámonos como hermanos y trabajemos para más adelante, como Dios quiere" (IMC, 2011, p. 30). La resistencia social aquí expresada se define a partir

de Proyecto Nasa han sido producción, educación, salud, vivienda y evangelización. 
de la motivación espiritual cuyo propósito es la defensa de la cultura con la adjudicación de la religiosidad católica.

La pedagogía liberadora del padre Álvaro Ulcué se visualiza a partir de los mensajes que él realizó en cada encuentro, en cada misa, en cada reunión, en cada capacitación (IMC, 2011, P. 140); pues, el mensaje liberador siempre fue "escuchen y practiquen", la enseñanza misma está intrínsecamente relacionada con el accionar, legado de Álvaro que en las comunidades Nasa se ha multiplicado con el lema de "caminar la palabra”, es lo que para el pensamiento filosófico occidental ha llamado la praxis revolucionara y el ser sentipensante.

Relacionar el lema Nasa de caminar la palabra tiene estrecha relación con la idea del "compromiso", debido a que el compromiso para hacer liberación social debe estar relacionado con la construcción de una ciencia para la liberación, donde sea la misma comunidad quien se apodere de su accionar político y filosófico.

La idea de formar a la comunidad para la liberación social y cultural era en Álvaro Ulcué un camino a seguir, en esta medida la educación liberadora en Álvaro ha debido estar coaccionada con el concepto de compromiso, que Fals Borda (2009) definió como "la acción o la actitud del intelectual que, al tomar conciencia de su pertenencia a la sociedad y al mundo de su tiempo, renuncia a una posición de simple espectador y coloca su pensamiento a su arte al servicio de una causa" (p. 243). Teniendo en cuenta el concepto de compromiso según Fals Borda, se puede resumir que Álvaro Ulcué Chocué era un comprometido por la liberación social del pueblo Nasa.

\section{CONCLUSIÓN}

Es necesario continuar fortaleciendo los distintos espacios que se mantienen en su idea indígena en contra de procesos modernizadores que atenten contra la vida de la naturaleza, puesto que podrán leer la globalización y la aparición de diferentes concepciones de representación, no como una amenaza, sino como la oportunidad de ver fallas, logrando mejorar en las generaciones, el trabajo de socializar, de concientizar.

Se abre la discusión del reconocimiento por parte de las instituciones públicas como entes territoriales de diversidad cultural. La necesidad de forjar la identidad en los jóvenes Nasa debido a los peligros que emana en la cultura occidental (la nueva manera de ejercer aculturación) se hace valer en la construcción de una educación propia. 
Resulta relevante decir como apunte final, que a pesar de los múltiples choques que se ejercen desde el Estado colombiano y la sociedad de pensamiento eurocéntrico, las comunidades indígenas Nasa del norte del Cauca continúan su legado histórico de resistencia cultural donde la autonomía ligada al Derecho Mayor y la Ley de Origen retoman el mito haciéndolo vivo, lo cual se presencia en el empoderamiento político de la guardia indígena y la decisión de recuperar la tierra.

La resistencia social en la actualidad, se traduce en mayor autonomía con respecto al sistema de evaluación, aunque el presupuesto de la educación indígena sea manejado por los propios pueblos, este debe estar acorde a las exigencias globales del sistema imperante, es decir, que aún existe una dominación política con respecto al tipo de formación académica de la juventud indígena. El ejercicio en este caso para los pueblos indígenas latinoamericanos está en contrarrestar el sistema de evaluación educativa y crear un sistema de evaluación propio, que esté acorde a la realidad de los pueblos.

\section{REFERENCIAS BIBLIOGRÁFICAS}

Acosta, Alberto (2010). "El buen vivir en el camino del post-desarrollo. Una lectura desde la Constitución de Montecristi". Recuperado en: https://www.fuhem.es/media/cdv/file/biblioteca/Analisis/Buen_vivir/Buen_vivir_posdesarroIlo_A._Acosta.pdf

Alcaldía de Toribío. (2015). Línea de indicadores socioeconómicos. Diagnóstico de condiciones sociales y económicas. Recuperado de http://www.gobernaciondelcauca.gov.co/

Asociación de Cabildos Indígenas de la zona Norte del Cauca, ACIN (2008). Somos alzados en bastones de mando. Recuperado por: http://www.desorg.org/titols/somos-alzados-en-bastones-demando/

Beca, N; Maya, D y Opocue, E. (2015). La identidad amenazada: la cultura Nasa en el presente de los jóvenes del resguardo indígena de Toribío, Municipio de Toribío (tesis de maestría). Universidad del Cauca, Popayán, Colombia.

Chantal, M. (1999). El retorno de lo político. Comunidad, ciudadanía, pluralismo y democracia radical. Buenos Aires: Paidós.

Colombia: Las contradicciones de "Caucannabis". (21 de julio de 2016). Servindi Servicios de Comunicación Intercultural. Recuperado de: https://www.servindi.org/printpdf/59107

Consejo Regional Indígena del Cauca [CRIC]. (2009). Caminando la palabra de los congresos del Consejo Regional Indígena del Cauca, CRIC, 1971-2009. Popayán: ARTEMI.

Defensoría del Pueblo (2014). Derecho a la autonomía de los grupos étnicos en Colombia. Boletín No. 2. Recuperado de: http://www.defensoria.gov.co 
El país (2017). Por los cañaduzales del Valle sacan droga para Chile y el Caribe, (Diario el País, 1 de marzo de 2017). Recuperado de: http://www.elpais.com.co/judicial/por-los-canaduzales-del-valle-sacan-droga-para-chile-y-el-caribe.html

Fals Borda, O. (2009). Una sociología sentipensante para América Latina. Buenos Aires: Siglo del Hombre editores

Gonzalez, B. (1996). Economías fundacionales: diseño del cuerpo ciudadano. En B. GONZALEZ STEPHAN. (Comp.), Cultura y Tercer Mundo 2. Nuevas identidades y ciudadanías. Caracas, Venezuela: Nueva Sociedad.

Instituto para Misiones la Consolata. (2011). Álvaro Ulcué Chocué Nasa pal hoy. Semilla y Camino. Popayán, Colombia: Instituto para Misiones la Consolata

La Mota, Blog. (2015). El interminable ocaso de la ciudad perdida de la marihuana. [Entrada de Blog]. Recuperado de https://www.lamota.org/es/blog/ocasociudad-perdida-marihuana/

Lemaitre, J. (2009). El derecho como conjuro: fetichismo legal, violencia y movimientos sociales. Universidad de los Andes. Bogotá, Colombia: Siglo del Hombre

Oficinas de las Naciones Unidas contra la Droga y el Delito [ONUDC]. (2016). Colombia, monitoreo de territorios afectados por cultivos ilícitos 2015. Recuperado de http://www.onudc.org/

Peña Collazos, Wilmar. (2009). El estudio de caso como recurso metodológico apropiado a la investigación en ciencias sociales. Revista de educación y desarrollo social. Vol. 3. No. 2. Julio-diciembre de 2009. Universidad Militar "Nueva Granada". pp. 180-195
Quijano, A. (2000). Colonialidad del poder, eurocentrismo y América Latina, parte de La colonialidad del saber: eurocentrismo y ciencias sociales. Perspectivas Latinoamericanas. Edgardo Lander (comp.) CLACSO, Consejo Latinoamericano de Ciencias Sociales, Buenos Aires, Argentina. Julio de 2000. p. 246. Disponible en: http://bibliotecavirtual.clacso.org.ar/ar/libros/lander/quijano.rtf

Rueda Ortiz, R.; Fonseca Díaz, A. y Ramírez Sierra, I. (EDS.). (2013). Ciberciudadanías. Cultura política y creatividad social. Bogotá: UPN Presentación. Rocío Rueda Ciberciudadanías, cultura política y creatividad social. Pp. 25 -32 y Cap. Resistir para salvar a vida. Creatividad política y educación. El caso de los cabildos indígenas del norte del Cauca. 115-135.

Uribe, H. y Ramirez A. (2014). Sentidos de lugar y movimiento social: indígenas de Toribío y defensa de su territorio en Colombia Recuperado de: https://www.sciencedirect.com/science/article/pii/S1665857414700997

Zibechi, R. (2008). América Latina: Periferias urbanas, territorios en resistencia. Bogotá: Desde Abajo.

\section{PARA CITAR ESTE ARTÍCULO:}

Beca, N. y Lagares O. (2017). Alternativas de poder político en los movimientos socialesrurales de Colombia: caso Organización Indígena del Norte del Cauca. Collectivus, Revista de Ciencias Sociales, 4(2), 36-54.

DOI: http://dx.doi.org/10.15648/Coll.2.2017.3

Recibido: 23/03/2017 Aprobado: 5/06/2017 